\title{
Using Oral and Intranasal Dosage Forms of Ketamine for Managing Treatment-Resistant Depression: A Review of the Literature
}

Patrick Arthur Twohig, ${ }^{1}$ Vaughn Huckfeldt.

\begin{abstract}
A lack of effective treatment for patients with treatment-resistant depression (TRD) has led to the evaluation of ketamine, an N-methyl-D-aspartate receptor antagonist. Despite the demonstrated short-term benefits of using intravenous (IV) ketamine, side effects and the difficulty in administering ketamine outside the health-care setting has raised interest in alternative dosage forms. Research articles evaluating oral or intranasal (IN) ketamine were retrieved from the PubMed database. Patients who received oral or IN ketamine experienced a similar reduction in depressive symptoms within 24 hours of treatment and fewer side effects compared to patients who received IV ketamine. Novel administration forms of ketamine provide an opportunity for patients with TRD to achieve remission with fewer adverse side effects. Future studies should continue to evaluate these administration strategies in the hope of promoting ketamine's use outside health-care settings and for longer time periods.
\end{abstract}

Keywords: Ketamine; Depressive Disorder, Treatment-Resistant; Administration, Oral; Administration, Intranasal; Administration, Intravenous (Source: MeSH, NLM).

About the Author: Patrick Twohig is currently a fourth-year medical student at Saba University School of Medicine, graduating in 2017. He completed his undergraduate studies and $\mathrm{MPH}$ in Canada.
Submission: Aug 15, 2015

Acceptance: Jul 08, 2016

Publication: Jul 27, 2016

Process: Peer-reviewed

\section{Introduction}

Depression affects over 350 million people worldwide. ${ }^{1}$ Major depressive disorder (MDD) is defined as a patient demonstrating at least five of the following nine symptoms for more than two weeks: depressed mood, poor sleep, loss of interest in daily activities or hobbies an individual used to enjoy, feelings of guilt or worthlessness, reduced energy or chronic fatigue, poor concentration, lack of appetite or five percent change in weight (gain or loss), physical and/or psychomotor agitation/retardation, and recurrent suicidal thoughts. ${ }^{2}$

The current standard of care for depression is primarily pharmacologic therapies that can alter neurological function of monoaminergic receptors within the central nervous system (CNS). These include serotonin selective reuptake inhibitors (SSRIs), serotonin-norepinephrine reuptake inhibitors (SNRIs), tricyclic antidepressants (TCAs), and anti-psychotics. Treatment-resistant depression (TRD) is defined as MDD that does not adequately respond to treatment after appropriate courses of time with at least two anti-depressants. ${ }^{3}$ Inadequate response can be classified as either a complete lack of response or as the patient's failure to achieve complete remission. ${ }^{4}$ Unfortunately, SSRIs and other first-line pharmaceutical treatments for depression take days or weeks to show clinical improvement, and produce an adequate response in less than two-thirds of patients. ${ }^{5}$

Despite the lack of research into novel treatments for TRD, one new therapy that has been tested to try and achieve better outcomes for patients who have not had success with more traditional pharmacotherapies is ketamine. ${ }^{6,7}$ Ketamine is categorized as an N-methyl-D-aspartate (NMDA) receptor antagonist, but it has been identified to affect the metabolism of acetylcholine, opioids, monoamines, and interact with multiple ion channels throughout the body. ${ }^{8}$ Ketamine can be administered in intravenous (IV), intranasal (IN), and oral forms, among others. It is metabolized into norketamine, the more abundant and active metabolite, and dehydronorketamine, the inactive metabolite. IV forms of ketamine produce plasma concentrations of norketamine that remain below initial ketamine levels, whereas oral forms produce much higher norketamine levels compared to initial ketamine doses. ${ }^{8}$

Evidence from numerous studies implicates alteration in the functions of the prefrontal, subcortical, and limbic brain systems in MDD. ${ }^{9,10}$ These regions of the brain are responsible for regulating executive functions like decision-making, emotional-processing, and social behavior. ${ }^{10}$ Patients suffering from MDD have been shown to have increased sensitivity to negative stimuli, such as pain and suffering, which directly relates to increased activity in the limbic and subcortical regions. By contrast, patients in remission from MDD commonly show increased activity in the pre-frontal cortex (PFC), which directly relates to the upregulation of glutamate activity in the PFC." Ketamine is an attractive alternative treatment for TRD due to its ability to simultaneously reduce neural activity in the limbic and subcortical regions while increasing activity in the PFC. ${ }^{11-14} \mathrm{~A}$ single IV infusion of ketamine has been shown to improve the mental well-being of TRD patients in as little as thirty minutes. ${ }^{15,16}$ This could make ketamine a viable treatment option in patients who are unsuccessfully treated with conventional anti-depressant

${ }^{1}$ Saba University School of Medicine, Caribbean Netherlands. 
therapies. ${ }^{17}$

Despite the potential of ketamine for the treatment of MDD, there are several factors that have limited its use in the United States and Canada, among other countries. Firstly, ketamine treatments are expensive and given that the United States Food and Drug Administration has not yet approved ketamine for the treatment of depression, these costs are not covered by insurance (Available from: http://www.rxlist.com/script/main/art. asp?articlekey $=184155$, cited $2015 \mathrm{Apr} 11$ ). Secondly, ketamine treatments are currently limited to IV administration by health care professionals which can make it more difficult for patients to access treatment. ${ }^{18}$ Lastly, ketamine can cause side effects such as dissociative amnesia, hallucinations, changes in blood pressure, and decreased cognition. ${ }^{8}$ Although these impairments are temporary, ketamine has only been tested over short time periods, which raises concern regarding its potential long-term impacts on mental function. ${ }^{19-21}$

Although IV ketamine has demonstrated rapid antidepressant effects, its disadvantages has led to the investigation of IN or oral dosage forms of ketamine treatment. ${ }^{6,18}$ The major goals of these alternative dosage forms are to reduce the dose required to achieve a therapeutic effect and to enable patient self-administration. Oral administration requires greater metabolism in the liver, which despite having a lower bioavailability, produces higher serum norketamine levels, which has been associated with the increased potency of analgesia as well as prolonged duration of action. ${ }^{8}$ IN ketamine, which has been successfully used for other clinical purposes including pediatric operations, migraine headaches and chronic pain, has been shown to be safe, effective, and equally as potent as IV ketamine. ${ }^{8}$ This success could result in reduced doses for TRD patients, which may limit the risk of adverse effects.

This paper aims to review the current evidence behind the use of oral and IN ketamine in treating patients with TRD. A comparison will be made between these novel dosage forms and the pre-existing body of evidence regarding the use of IV ketamine for TRD. Success of these interventions will be based on treatment response, length of symptom remission period, and presence of side effects. It is hypothesized that oral and IN dosage forms of ketamine are as effective as IV forms in the management of TRD.

\section{Search Strategy and Selection Criteria}

The database PubMed (1964-17 December 2014) was searched using the terms: "ketamine" and "depression", and two separate searches were conducted using these two terms along with "intranasal administration " and "oral administration". In PubMed, all of these terms were searched both as basic terms and "MeSH" terms. The authors examined titles and abstracts that assessed the use of oral or (IN) ketamine in: (1) human subjects; (2) patients with (TRD); (3) randomized controlled trials (RCTs), case-control, cohort, or case series; (4) published in English; and (5) full reports (not just abstracts). This information was extracted and organized in tabular form. Articles that did not meet these criteria were excluded. Full text articles were obtained and classified according to the route of administration that was used in the study (IN or oral). Articles that did not address the administration of oral or IN ketamine were
Figure 1. Flow Diagram for Article Screening and Selection

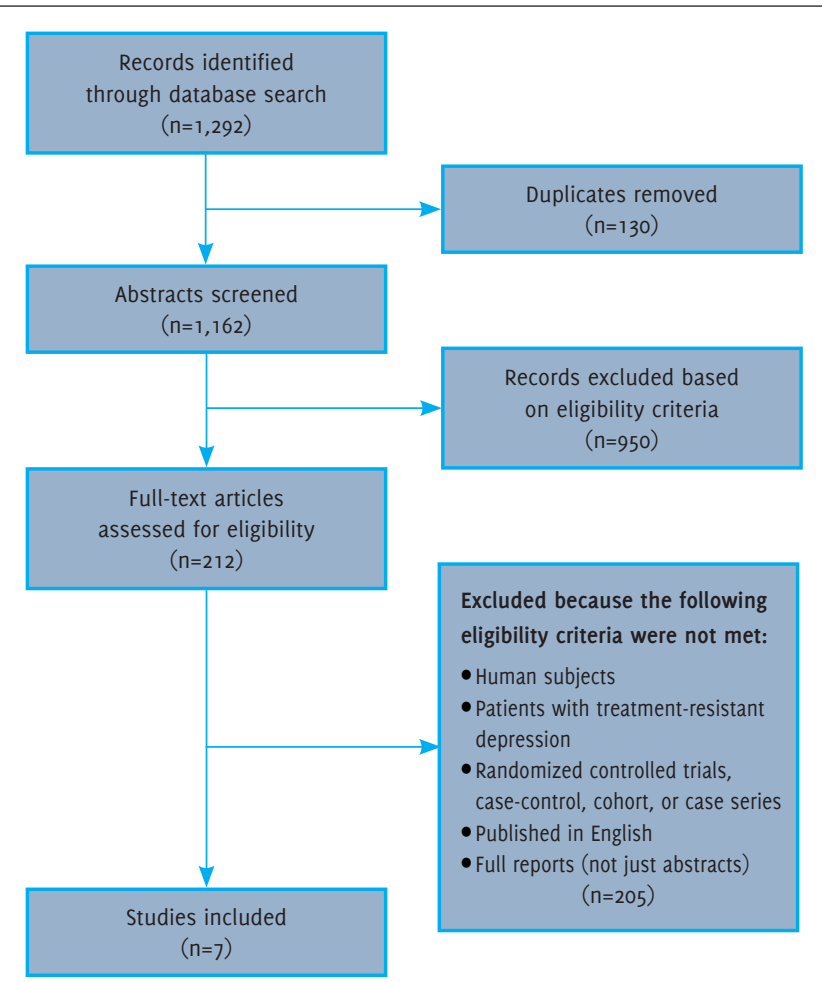

also excluded. Figure 1 provides an outline of the methodology used to retrieve articles for this review. The quality of a study was evaluated using the criteria from the Centre for Evidence-Based Medicine, Oxford (Available from: http://www.essentialevidenceplus.com/product/ebm_loe.cfm?show=oxford, cited 2014 Dec 17).

\section{Results of the Search}

As outlined in Figure 1, seven articles were included in this review. Two articles evaluated IN administration of ketamine, one being RCT while the other is a case-series. The other five articles evaluated the efficacy of oral administration, but have been subdivided based on the demographics of the patient population in the study. Three studies focused specifically on patients with TRD, and all three are case studies. The other two studies on oral administration evaluated efficacy in patients with TRD and a history of anxiety disorder. One of these is a case-series, and the second is an open-label trial. These articles are outlined in Table 1 and will be described in further detail below.

\section{Intranasal Ketamine}

The first of two studies conducted to date on the use of IN ketamine in TRD was a case-series comparing bipolar symptoms in 12 pediatric patients with TRD one to two weeks before and after treatment with six $10 \mathrm{mg}$ doses of IN ketamine over a 20 week period. ${ }^{22}$ The second was a randomized-controlled cross-over trial which used two $50 \mathrm{mg}$ IN ketamine doses and IN saline as control over two days in 18 patients with MDD. ${ }^{18}$ Patients in the first study reported a $48 \%$ reduction $(p<0.001)$ in symptom severity and improvements in attention, executive function, and mood after receiving treatment according to the mean values of the Child bipolar questionnaire, Overt aggression scale, and Yale-Brown obsessive-compulsive scale. ${ }^{22}$ 
Table 1. Studies Evaluating Intranasal/Oral Ketamine in Treatment-Resistant Depression

\begin{tabular}{|c|c|c|c|}
\hline Study & Study Design & $\begin{array}{l}\text { Level of } \\
\text { Evidence* }\end{array}$ & Study Population \\
\hline $\begin{array}{l}\text { Papolos et } \\
\text { al (2013) }\end{array}$ & Case series & 4 & $\begin{array}{l}12 \text { pediatric (6-19 } \\
\text { years) patients with } \\
\text { bipolar disorder and } \\
\text { "fear of harm" phe- } \\
\text { notype }\end{array}$ \\
\hline $\begin{array}{l}\text { Lapidus et } \\
\text { al (2014) }\end{array}$ & $\begin{array}{l}\text { Randomized } \\
\text { controlled } \\
\text { trial }\end{array}$ & $1 b$ & $\begin{array}{l}18 \text { patients with major } \\
\text { depressive disorder } \\
\text { completed } 2 \text { treatment } \\
\text { days with intranasal } \\
\text { ketamine ( } 50 \mathrm{mg} \text { ) or sa- } \\
\text { line solution (control) }\end{array}$ \\
\hline $\begin{array}{l}\text { Iglewicz et } \\
\text { al (2013) }\end{array}$ & Case series & 4 & $\begin{array}{l}31 \text { inpatients receiving } \\
\text { hospice care being } \\
\text { treated with ketamine } \\
\text { for depression }\end{array}$ \\
\hline
\end{tabular}

\begin{tabular}{llll}
$\begin{array}{l}\text { Irwin et al } \\
(2013)\end{array}$ & $\begin{array}{l}\text { Open-label } \\
\text { proof-of-con- } \\
\text { cept trial }\end{array}$ & $2 b$ & $\begin{array}{l}\text { 14 patients with de- } \\
\text { pression or depression } \\
+ \text { anxiety }\end{array}$ \\
\hline $\begin{array}{l}\text { Irwin Ct } \\
\text { Iglewicz } \\
(2010)\end{array}$ & Case series & 4 & $\begin{array}{l}\text { 2 patients with depres- } \\
\text { sion + anxiety }\end{array}$ \\
\hline
\end{tabular}

Comparison of bipolar symptoms pre-

(1-2 weeks prior) and post-treatment with six 10mg doses of intranasal ketamine over a 20 week period. Measured using the child bipolar questionnaire, overt aggression sca
Yale Brown obsessive compulsive Yale Brown obsessive compulsive
scale, and clinical administered dissociative states scale.

\section{Change in depression severity 24} hours after treatment using Montgomery-Asberg Depression Rating gomery-Asberg Depression Rating
Scale. Also measured changes in self-reported depression, anxiety, and adverse effects.

Retrospective review of patients therapeutic improvement, global improvement, time to therapeutic effect, and side effects of oral ketamine during 4 time intervals (days 0-1, 2-3, $4-7$, and 8-21) over 21 days using Clinical Global Impression Scale.

Rating of overall depression and anxiety symptoms at baseline, and at days $3,7,14,21$, and 28 during course of daily oral ketamine $(0.5$ $\mathrm{mg} / \mathrm{kg}$ ) over 28 day trial.

Rating of overall depression and anxiety symptoms using the Hospital Anxiety Depression Scale at $1 \mathrm{~h}, 2 \mathrm{~h}$, and day 8 (2nd patient) or day 15 (1st patient) after a $0.5 \mathrm{mg} / \mathrm{kg}$ dose of oral ketamine.

\begin{tabular}{llll}
$\begin{array}{l}\text { Lara et al } \\
(2013)\end{array}$ & Case series & 4 & $\begin{array}{l}26 \text { outpatients with } \\
\text { unipolar or bipolar } \\
\text { depression showing } \\
\text { unsatisfactory response } \\
\text { to at least } 4 \text { other } \\
\text { pharmacological } \\
\text { treatments }\end{array}$ \\
\hline $\begin{array}{l}\text { Paslakis et } \\
\text { al (2010) }\end{array}$ & Case series & 4 & $\begin{array}{l}\text { 4 patients with de- } \\
\text { pression }\end{array}$
\end{tabular}

Patient ratings of therapeutic effects and tolerability of sublingual ketamine $0.5 \mathrm{mg} / \mathrm{kg}$ every $2-3$ days for no more than 6 months.

Therapeutic outcomes, patient tolerance, and side effects to daily $1.25 \mathrm{mg} / \mathrm{kg}$ of oral S-ketamine for a maximum of 14 days.

\section{Outcomes and Results}

Intranasal ketamine led to large reductions in mania, fear of harm, and aggression. Improvements in mood, anxiety, behavioral symptoms, attention/executive functions, insomnia, parasomnia, and sleep inertia were also observed post-treatment.

Significant improvement in depressive symptoms at 24 hours in patients given ketamine compared to placebo. Minimal psychomimetic, dissociative, or hemodynamic side effects were observed.

Significant therapeutic improvements were seen during the first 7 days (especially in the first day). Clobal improvement was improved for all 21 days. A majority of patients experienced no side effects, and any recorded side effects did not significantly impair functioning.

Significant improvements in depressive and anxiety symptoms were seen throughout the 28 day trial. Maximum improvements were seen at days 14 and 3 for each symptom, respectively. Side effects were rare.

Significant improvements in depressive and anxiety symptoms were seen in both patients throughout the course of follow up. Side effects were minimal in both patients.

Rapid, sustained improvements were seen in mood level and stability, cognition and sleep in $77 \%$ of patients. Only mild side effects were seen in some patients. Remission was achieved in some patients after stopping treatment.

Two patients with melancholic depression saw rapid and sustained improvements in mood. Two patients with somatic symptoms and other comorbid personality disorders showed minimal benefit from treatment. No side effects were observed.

\footnotetext{
* Levels of evidence in a research article:

$1 \mathrm{a}=$ Systematic reviews (with homogeneity) of randomized controlled trials

$\mathrm{lb}=$ Individual randomized controlled trials (with narrow confidence interval)

$1 \mathrm{C}=$ All or none randomized controlled trials

$2 \mathrm{a}=$ Systematic reviews (with homogeneity) of cohort studies

$2 b=$ Individual cohort study or low quality randomized controlled trials (e.g. $<80 \%$ follow-up)

$2 \mathrm{c}=$ "Outcomes" Research; ecological studies

$3 a=$ Systematic review (with homogeneity) of case-control studies

$3 \mathrm{~b}=$ Individual case-control study

$4=$ Case-series (and poor quality cohort and case-control studies)

$5=$ Expert opinion without explicit critical appraisal, or based on physiology, bench research or "First principles"
}

Therapeutic effects were typically reached within one hour of treatment, and all patients had a reduction in symptoms after 24 hours. Ketamine treatment kept all patients in remission from symptoms, but as the effects of the drug wore off, symptoms recurred.

Patients in the treatment group of the second study reported a significant reduction in their MDD symptoms compared to placebo. The mean difference in scores using the Montgomery-Asberg Depression Rating Scale was $7.6 \pm 3.7(95 \% \mathrm{Cl} 3.9-11.3$, p $<0.001) .{ }^{18}$ Additionally, eight patients ( $44 \%$ ) experienced these reductions within 24 hours of receiving treatment compared to only one patient $(6 \%)$ in the control group (number needed to treat $=2.6$ ). Patients in this study ${ }^{18}$ reported minimal side effects from treatment, most commonly being dissociation $(42 \%)$, poor memory $(37 \%)$, and fatigue $(26 \%)$ while more than $65 \%$ of patients in the first study ${ }^{22}$ reported experiencing a loss of balance, dissociative effects, and dizziness as a result of treatment according to the Clinician administered dissociative states scale. These symptoms, with rare exceptions, were gone within 24 hours. ${ }^{22}$ 


\section{Oral Ketamine \\ Patients with TRD}

Three studies in which oral ketamine was administered to patients with TRD but no other significant comorbidities met the inclusion criteria of this review. A retrospective case series was conducted among 31 inpatients with TRD, a majority (29 of 31 patients) of whom received only oral forms of ketamine, and 22 of 31 received only a single dose of $0.5 \mathrm{mg} / \mathrm{kg}$ during the duration of the study. ${ }^{23}$ Coals of this study were to evaluate therapeutic improvement, time to therapeutic effect, and any adverse effects for three weeks following treatment using the Clinical Global Impression Scale. ${ }^{23}$ They found that $93 \%$ of patients had a positive response in days $0-3$ and $80 \%$ in days 4-7 post-ketamine, and that more than $50 \%$ of patients had improved outcomes during the entire three weeks of study. No patients rated their symptoms as worse than before treatment. Seven subjects (45\%), however, experienced disorientation, $36 \%$ had hallucinations or sedation and $15 \%$ had insomnia, delusions or anxiety. ${ }^{23}$

Another study evaluated the effects of $3 \mathrm{mg}$ sublingual doses of ketamine every two to three days for no more than six months in 26 outpatients with TRD. ${ }^{24}$ Although this study evaluated sublingual ketamine, an exception was made to the inclusion criteria outlined in the methods due to the dearth of literature on this topic and comparability of the results and study design. Unlike the previous study, ${ }^{23}$ effects of the treatment in this study were determined based on patients' self-rated mood (using a scale of 0-10) 90 minutes after each treatment. Self-rated mood, cognition, and sleep increased by at least two points in $77 \%$ of patients after 90 minutes. Only $12 \%$ of patients reported post-treatment side effects, of which light-headedness was most common. These effects lasted less than thirty minutes. Remission was achieved in $23 \%$ of patients after stopping ketamine treatment. The length of remission varied among patients, but ranged from seven to 36 days post-treatment.

A third case series evaluated therapeutic outcomes in four patients with TRD after administering daily oral doses of $1.25 \mathrm{mg} /$ $\mathrm{kg}$ of ketamine for a maximum of 14 days. ${ }^{25}$ Using the Hamilton Rating Scale for Depression (HRSD), two of the patients had self-rated 12 and 13-point reductions in HRSD scores in the first week while the other two had a one point reduction and one point increase, respectively. Reports of statistical significance were not provided because the study was a case series. The variation in response was suspected to be due to comorbid conditions, including personality disorders. None of the four patients in this case series experienced any side effects.

\section{Patients with TRD + Anxiety}

Many patients who suffer from depression also have comorbid symptoms that can affect the success of treatment, which may be a major reason why these patients are resistant to traditional treatment approaches. ${ }^{25}$ Both of the studies included in this review were conducted using oral ketamine in patients with TRD + anxiety. ${ }^{19,26}$ Both studies used a consistent dosage of 0.5 $\mathrm{mg} / \mathrm{kg}$, and the primary tool used in both studies to measure therapeutic outcomes in patients was the Hospital Anxiety Depression Scale.

A case series was conducted on two patients with data co- llected after one and two hours for both patients, then again at day eight (2nd patient only) and day fifteen (1st patient only) after treatment. ${ }^{26}$ Both patients showed an approximately $50 \%$ improvement in both anxiety and depressive symptoms (statistical significance was not reported), and neither experienced side effects or changes in cognitive function, as measured through a Mini-Mental State Exam. Another trial used an "open-label" design with 14 patients, in which no randomization occurs, all 14 patients received treatment, and patients were allowed to continue taking other prescribed medications. ${ }^{19}$ Patients' ratings of overall depression and anxiety symptoms were collected at baseline and at days 3, 7, 14, 21, and 28. The eight subjects who completed the trial all showed more than a $30 \%$ improvement in anxiety and depressive symptoms, with maximums being reached at day three for anxiety and day 14 for depression. The other six patients withdrew from the study due to either a lack of response to ketamine or as a result of mental status changes unrelated to the ketamine treatment. Thirteen percent of patients in the study reported experiencing diarrhea and insomnia. ${ }^{19}$

\section{IV vs. Alternative Dosage Forms}

This review found that there have been 15 case studies, 11 open label trials, and nine RCTs studying the effects of ketamine in treating MDD. Of the 15 case studies, nine evaluated IV administration, four oral administration, two intramuscular administration, and one IN administration. Ten of the open label trials evaluated IV administration and one evaluated oral administration. Eight of the RCTs assessed IV administration, while one assessed IN administration. The forthcoming discussion will begin by comparing and contrasting the study design, response to treatment, and side effect profiles among the IV, oral, and intranasal studies.

\section{Study Design}

Single-infusion RCTs. The first study on the use of single-dose IV ketamine was an RCT where eight patients were either given a $0.5 \mathrm{mg} / \mathrm{kg}$ infusion of ketamine over 40 minutes or saline as control. ${ }^{27} \mathrm{~A}$ common feature shared by all follow-up RCTs on IV administration is the administration of $0.5 \mathrm{mg} / \mathrm{kg}$ of ketamine over 40 minutes. Another common feature to three of the nine RCTs is that the patients suffered from both TRD and anxiety disorder. ${ }^{728,29}$ The other three RCTs investigating IV dosage forms only evaluated patients with TRD. ${ }^{30,31} \mathrm{~A}$ unique feature of one of the RCTs was that patients were given a two-week drug-free period before initiating treatment, and were evaluated at eight time intervals post-infusion. ${ }^{16}$

The final RCT was the first study of its kind because it evaluated the administration of IN ketamine to patients with TRD. ${ }^{18} \mathrm{~Pa}$ tients in the study group received a total of $50 \mathrm{mg}$ of ketamine over 20 minutes. This is an interesting approach, as the lack of body weight adjustment could have drastically altered the effects on individual patients depending on their body size. Another confounding factor that could affect the efficacy of this therapy is that $15 \%$ of patients in the study had a history of medical or recreational drug use. ${ }^{18}$

Open label trials. A novel approach used in one open label trial involved repeated doses of ketamine for patients who had shown an initial response to treatment. ${ }^{32}$ After the last infusion, 
patients were monitored twice per week for one month, or until a relapse in symptoms occurred. Unlike this trial, ${ }^{32}$ some studies just provided the single dose in the open-label format, whereas two others pre-treated patients with lamotrigine (300 $\mathrm{mg}$ ) and then did a subsequent randomization of patients who responded to the initial ketamine treatment to receive riluzole (100-200 mg) or placebo to try and not only minimize the psychomimetic side effects of ketamine but also prolong its pharmacologic activity in the body. . $^{30,33}$ These side effects of ketamine have been associated with increased pre-synaptic glutamate release..$^{8,34}$ It was hoped that by using additional drugs that act on glutamate receptors, the acute neuropsychiatric effects of ketamine would be reduced.

The final open label trial followed patients intermittently for three weeks after they received a $0.5 \mathrm{mg} / \mathrm{kg}$ dose of oral ketamine. ${ }^{19}$ It is suggested that future studies include more frequent follow-up using standardized, validated clinical tools, and measure outcomes over longer periods of time.

Case series. Nine of the 15 case series conducted to date have focused on IV administration. Of these, six have used the most common dosage formulation of $0.5 \mathrm{mg} / \mathrm{kg}$ injected over a time frame of 40-60 minutes. However, one study used a smaller dose of $0.3 \mathrm{mg} / \mathrm{kg}$ that was delivered over five days. ${ }^{35}$ Two other studies involved larger doses of ketamine $(1-1.5 \mathrm{mg} / \mathrm{kg})$, which were administered intramuscularly (IM). ${ }^{66,37}$ The other four case series to date have studied the two more novel dosage forms of ketamine - one IN and the other three using oral forms. ${ }^{22-25}$

\section{Response to Treatment}

Single-infusion RCTs. The first RCT found that ketamine reduced HRSD scores within four hours, and that scores were reduced by more than $50 \%$ by 72 hours post-infusion. ${ }^{15}$ Each of the other seven RCTs on IV administration conducted to date had a greater than $50 \%$ reduction in scores within 24 hours according to standardized measures of clinical depression. In a follow-up $\mathrm{RCT}$, it was found that $35 \%$ of patients maintained this response and $12 \%$ sustained remission of symptoms for two weeks. ${ }^{16}$

A trial on IN ketamine found that $44 \%$ of patients had sufficient responses to treatment using MADRS scores within 24 hours compared to $6 \%$ of placebo. ${ }^{18}$ Despite the apparent lack of longer term response in this study, the number needed to treat was only 2.6, which was the lowest result of any of the RCTs. This indicates that, although blood concentration levels of IN ketamine were lower than with IV forms, IN ketamine was no less effective and merely dissipated more rapidly.

Open label trials. The repeated-infusion approach demonstrated an $85 \%$ reduction in MADRS scores at the completion of the trial. ${ }^{32}$ On average, relapse occurred 19 days after the sixth infusion. The other open label trials evaluating IV administration found consistent improvements in depressive symptoms 24 hours after treatment. ${ }^{28,30,38-42}$ However, it remains a mystery why some patients who initially respond to treatment relapse by 72 hours while others can remain in remission for more than two weeks. Although one group of researchers explained the variation between treatment groups to be a result of low sample sizes, ${ }^{33}$ this is unlikely given the relatively small size of all studies done to date on the use of ketamine for TRD. Other potential explanations for the wide variation in relapse times may include, but not be limited to, the impacts of ketamine on multiple neural pathways within the brain. ${ }^{12,41}$ Another potential explanation describes, for example, how patients who have a family history of alcohol dependence have shown fewer dissociative effects and greater improvements in mood compared to control groups. ${ }^{6}$ These findings have been supported in other research, which have also found that patients associated with alcohol dependence have better short-term outcomes and faster improvement time compared to patients without a family history of alcohol dependence. ${ }^{40,43,44}$

The only open label trial that has been conducted on oral administration of ketamine found a similar response rate $(57 \%)$ to that in other trials involving IV administration. ${ }^{19}$ One major difference between this trial and others using IV administration was the prolonged time to therapeutic effect. Oral forms of ketamine took 14 days to maximize improvements in symptoms of depression rather than several hours as seen with IV forms. Despite this delayed onset time, improvements in symptom control were more prolonged after oral administration, as patients experienced remission for up to four weeks.

Case series. There is a high degree of variation in the dosage forms and timing of dosing in the case series that have been conducted. This makes it difficult to draw general conclusions or to compare and contrast the results of this research. Consistency in side effects was noted among these case studies when compared to open label trials using IV administration. Transient changes were noted in some patients soon after infusion, but these appeared to be mild and did not persist beyond 24 hours. ${ }^{45}$

With little exception, each of the five case series (four oral, one IN) conducted on novel dosage forms found that patients had substantial post-treatment reductions in symptoms of depression, anxiety, and other associated symptoms like insomnia. Variation in the onset of therapy as well as the time to relapse appeared to be most strongly correlated to the volume and frequency of the dose. Out of the five studies, the study on sublingual ketamine used the most consistent and prolonged dosage frequency, providing $0.5 \mathrm{mg} / \mathrm{kg}$ every two to three days for up to six months. ${ }^{24}$ This provided an indication of ketamine's potential if used on a longer term basis. Although this study evaluated sublingual ketamine, this is still a more feasible treatment form compared to IV or IM administrations because it can provide the advantage of patient self-administration. Most studies to date have not continued dosing for this length of time, or had follow up beyond two weeks. This is an area of research that is lacking, denoting the importance of long-term evaluations of ketamine's impact on patients with TRD.

\section{Side Effects}

Despite the inroads that ketamine has demonstrated in relieving symptoms of TRD, studies consistently find that patients experience one or more psychomimetic, cognitive, or other detrimental side effects as a result of treatment. ${ }^{6,15}$ Although some of these effects may be described as mild and transient, the lack of evidence regarding long-term ketamine use raises concern over the neurological effects of more frequent and chronic ketamine use. Additionally, even if effects are mild and tem- 
porary, an analysis of how this can impact patients who are employed or must be functional with daily activities of living has yet to be established.

An open label trial found similar side effects to the single-infusion RCTs described previously. ${ }^{32}$ Most studies to date that have evaluated IV administration have discovered limited side effects in a select few patients, which dissipated within one day of infusion. ${ }^{6,24}$ However, this information should be weighed with caution given the lack of standardized testing that was used to interpret side effects. With one exception, ${ }^{31}$ most studies to date have not used validated data collection tools for evaluating side effects. This should be done in future studies so results can be more easily compared.

The administration of IN ketamine has demonstrated a relative lack of cognitive, psychomimetic, or other side effects. ${ }^{18}$ It is promising that the body of research conducted to date has demonstrated few severe or lasting side effects associated with ketamine treatment, regardless of dosage form..$^{4,5,46}$

\section{Limitations of the Included Studies}

All of the studies in this review were conducted with very small sample sizes. The largest study evaluated 31 patients, which lowers the power of the results and means the results may be less applicable to the broader population. Four of the seven studies in this review had statistically significant results. ${ }^{18,19,22,23}$ Another limitation of the studies presented in this review is the predominance of case series. This type of study lacks an appropriate control, making it a low-quality study design. As a result, ketamine is controlled to placebo, rather than with the currently accepted standard treatment. This highlights the need for future studies to use hypothesis-testing study designs such as cohort studies or RCTs with the aim of generating evidence-based results. Lastly, the varying degree of statistical significance reported in the seven studies included in this review may bring into question the true efficacy of IN and oral ketamine. ${ }^{24-26}$

Another issue is the degree of variation within the different population subtypes that are included as treatment groups. Interactions of ketamine with other drugs, comorbid conditions (e.g. anxiety disorder, bipolar depression), and the metabolism of individual patients may drastically alter the efficacy and potency of ketamine in patients with TRD. One study found that most patients with substance abuse disorders could not tolerate the withdrawal period prior to treatment. ${ }^{31}$ As a result, only patients who could withstand withdrawal from their medication(s) and the psychotropic side effects of ketamine continued with the study. These factors should be taken into consideration when analyzing and interpreting results from these studies.7.27

As shown in Table 1, the evidence in this review, while promising, lacks the quality and quantity that would allow for more definitive conclusions. Of the seven studies, only one is an RCT - the highest (and most desirable) level of evidence (Level 1), ${ }^{13}$ another is an open-label proof-of-concept trial, which is considered a low quality controlled trial (Level 2b), ${ }^{19}$ and the other five are case series (Level 4), the second-lowest level of evidence in research (Table 1). Lastly, studies that have evaluated the side effects patients experience post-ketamine treatment have not used objective, standardized, and validated clinical tools but rather data based solely on patients' self-reported feelings or subjective reports from family members. ${ }^{24}$ Furthermore, the lack of consistency with dosing raises questions about ideal dosing quantities and frequencies for different administration methods which should be studied over longer time periods. Despite the shortcomings of the available evidence, the consistent nature of the results demonstrates the need for larger population, stratified studies in double-blind, randomized controlled trials.

\section{Future Directions}

Now that more precise IV dosing quantities of ketamine have proven to be effective for TRD patients, a goal of future studies should be to determine more precise dosing quantities and frequencies for oral and IN administrations. This information can then be extended to trials on patients with TRD as well as other mental or physical comorbidities. This will provide a more accurate understanding of the reasons for various outcomes in these patients and how ketamine dosing can be altered so all patients with TRD can benefit from both rapid relief of symptoms and longer remission from depression.

More recent research efforts have focused on evaluating ketamine's molecular and pharmacologic activity. ${ }^{47-49}$ Studies have further demonstrated ketamine's rapid and long-lasting ability to increase glutamate levels in the ventral hippocampus and PFC via mammalian target of rapamycin (mTOR) signaling. ${ }^{47,48}$ Additional evidence has shown that ketamine's antagonism of NMDA receptors can trigger a cascade of molecular activity that prevents the degradation of mTOR signals, which in turn potentiates ketamine's anti-depressant effects. ${ }^{49}$ Continued evaluation of ketamine's pharmacologic potential may lead to the discovery of novel targets for rapid anti-depressant therapies in patients with TRD.

Another area of future research could be to find ways to optimize ketamine metabolism in the brain so its therapeutic effects can be prolonged. Two studies tried to optimize the delivery of IV ketamine and minimize side effects by pre-treating patients who initially responded to ketamine using lamotrigine and riluzole. ${ }^{30,33}$ However, this was unsuccessful at curbing remission compared to placebo, which highlights the need for further investigation into strategies for preventing relapse post-ketamine treatment. A better understanding of the action of ketamine on neural circuits in the CNS could allow for the development of other therapeutic combinations that enhance ketamine's beneficial effects. ${ }^{41}$

The positive findings in this review regarding the effectiveness of oral administration may not only make treatment with oral ketamine more attractive to patients but also reduce the risk of adverse outcomes associated with IV catheters, such as malfunction, infection, and thrombosis..$^{50,51}$ Although more research is needed in larger, more controlled research conditions, results from studies thus far can be used as a basis for future research. ${ }^{19}$

The studies on IN administration show that lower doses of ketamine can still have beneficial effects, and with fewer side effects than standard IV preparations. ${ }^{18,22}$ More trials into IN dosages may result in a better balance between maximizing 
clinical benefits and minimizing side effects.

\section{Conclusion}

The studies of IV, oral, and IN administration forms of ketamine in treating TRD support the hypothesis of this paper. Oral and IN administration forms of ketamine have demonstrated therapeutic outcomes in some patients with TRD. Further studies will be needed to verify this, but given the relative lack of effective therapies for TRD combined with the challenges of long-term maintenance of treatment, safety, and ease of administration of these novel dosage forms, more research is certainly warranted.

\section{References}

1. Marcus M, Yasamy MT, van Ommeren M, Chisholm D, Saxena S. Depression: a global public health concern. Geneva: World Health Organization Department of Mental Health and Substance Abuse; 2012.

2. American Psychiatric Association. Diagnostic and statistical manual of mental disorders. 5th ed. Washington, DC: American Psychiatric Association; 2013. 3. Wijeratne C, Sachdev P. Treatment-resistant depression: critique of current approaches. Aust N Z J Psychiatry. 2008 Sep;42(9):751-62.

4. Caddy C, Giaroli C, White TP, Shergill SS, Tracy DK. Ketamine as the prototype glutamatergic antidepressant: pharmacodynamics actions, and a systematic review and meta-analysis of efficacy. Ther Adv Psychopharmacol. 2014 Apr;4(2):75-99.

5. Katalinic N, Lai R, Somogyi A, Mitchell PB, Glue P, Loo CK. Ketamine as a new treatment for depression: a review of its efficacy and adverse effects. Aust $N$ Z J Psychiatry. 2013 Aug;47(8):710-27.

6. Naughton M, Clarke G, O'Leary OF, Cryan JF, Dinan TG. A review of ketamine in affective disorders: current evidence of clinical efficacy, limitations of use, and pre-clinical evidence on proposed mechanisms of action. J Affect Disord. 2014 Mar; 156:24-35.

7. Rodriguez Cl, Kegeles LS, Levinson A, Feng T, Marcus SM, Vermes D, et al. Randomized controlled crossover trial of ketamine in obsessive-compulsive disorder: proof-of-concept. Neuropsychopharmacology. 2013 Nov;38(12):247583.

8. Mathew SJ, Shah A, Lapidus K, Clark C, Jarun N, Ostermeyer B, et al. Ketamine for treatment-resistant unipolar depression: current evidence. CNS Drugs. 2012 Mar 1;26(3):189-204.

9. Krishnan V, Nestler EJ. Linking molecules to mood: new insight into the biology of depression. Am J Psychiatry. 2010 Nov; 167(11):1305-20.

10. Price JL, Drevets WC. Neurocircuitry of mood disorders. Neuropsychopharmacology. 2010 Jan;35(1):192-216.

11. Opler LA, Opler MG, Arnsten AF. Ameliorating treatment-refractory depression with intranasal ketamine: potential NMDA receptor actions in the pain circuitry representing mental anguish. CNS Spectr. 2016 Feb;21(1):12-22.

12. Abel KM, Allin MP, Kucharska-Pietura K, David A, Andrew C, Williams S, et al. Ketamine alters neural processing of facial emotion recognition in healthy men: an fMRI study. Neuroreport. 2003 Mar 3;14(3):387-91.

13. Breier A, Adler CM, Weisenfeld N, Su TP, Elman I, Picken L, et al. Effects of NMDA antagonism on striatal dopamine release in healthy subjects: application of a novel PET approach. Synapse. 1998 Jun;29(2):142-7.

14. Salvadore G, Cornwell BR, Sambataro F, Latov D, Colon-Rosario V, Carver F, et al. Anterior cingulate desynchronization and functional connectivity with the amygdala during a working memory task predict rapid antidepressant response to ketamine. Neuropsychopharmacology. 2010 Jun;35(7):1415-22. 15. Berman RM, Cappiello A, Anand A, Oren DA, Heninger GR, Charney DS, et al. Antidepressant effects of ketamine in depressed patients. Biol Psychiatry. 2000 Feb 15;47(4):351-4.

16. Zarate CA Jr, Singh JB, Carlson PJ, Brutsche NE, Ameli R, Luckenbaugh DA, et al. A randomized trial of an N-methyl-D-aspartate antagonist in treatment-resistant major depression. Arch Gen Psychiatry, 2006 Aug;63(8):856-64.
17. Warden D, Rush AJ, Trivedi MH, Fava M, Wisniewsk SR. The STAR*D Project results: a comprehensive review of findings. Curr Psychiatry Rep 2007 Dec; $9(6): 449-59$.

18. Lapidus KA, Levitch CF, Perez AM, Brallier JW, Parides MK, Soleimani L, et al. A randomized controlled trial of intranasal ketamine in major depressive disorder. Biol Psychiatry. 2014 Dec;76(12):970-6.

19. Irwin SA, Iglewicz A, Nelesen RA, Lo JY, Carr CH, Romero SD, et al. Daily oral ketamine for the treatment of depression and anxiety in patients receiving hospice care: a 28-day open-label proof-of-concept trial. J Palliat Med. 2013 Aug; 16(8):958-65.

20. Ionescu DF, Luckenbaugh DA, Niciu MJ, Richards EM, Slonena EE, Vande Voort JL, et al. Effect of baseline anxious depression on initial and sustained antidepressant response to ketamine. J Clin Psychiatry. 2014 Sep;75(9):e932-8. 21. Curran HV, Morgan C. Cognitive, dissociative and psychogenetic effects of ketamine on recreational users on the night of drug use and 3 days later. Addiction. $2000 \mathrm{Apr}$;95(4):575-90.

22. Papolos DF, Teicher MH, Faedda CL, Murphy P, Mattis S. Clinical experience using intranasal ketamine in the treatment of pediatric bipolar disorder/fear of harm phenotype. J Affect Disord. 2013 May;147(1-3):431-6.

23. Iglewicz A, Morrison K, Nelesen RA, Zhan T, Iglewicz B, Fairman N, et al. Ketamine for the treatment of depression in patients receiving hospice care: a retrospective chart review of thirty-one cases. Psychosomatics. 2015 JulAug;56(4):329-37.

24. Lara DR, Bisol LW, Munari LR. Antidepressant, mood stabilizing and precognitive effects of very low dose sublingual ketamine in refractory unipolar and bipolar depression. Int J Neuropsychopharmacol. 2013 0ct;16(9):2111-17. 25. Paslakis G, Gilles M, Meyer-Lindenberg A, Deuschle M. Oral administration of the NMDA receptor antagonist S-ketamine as add-on therapy of depression: a case series. Pharmacopsychiatry. 2010 Jan;43(1):33-5.

26. Irwin SA, Iglewicz A. Oral ketamine for the rapid treatment of depression and anxiety in patients receiving hospice care. J Palliat Med. 2010 Jul;13(7):903-8.

27. Niciu MJ, Luckenbaugh DA, Ionescu DF, Guevara S, Machado-Vieira R, Richards EM, et al. Clinical predictors of ketamine response in treatment-resistant major depression. J Clin Psychiatry. 2014 May;75(5):e417-23.

28. Diazgranados N, Ibrahim L, Brutsche NE, Newberg A, Kronstein P, Khalife $\mathrm{S}$, et al. A randomized add-on trial of an N-methyl-D-aspartate antagonist in treatment-resistant bipolar depression. Arch Gen Psychiatry. 2010 Aug;67(8):793-802.

29. Zarate CA Jr, Brutsche NE, Ibrahim L, Franco-Chaves J, Diazgranados N, Cravchik $A$, et al. Replication of ketamine's antidepressant efficacy in bipolar depression: a randomized controlled add-on trial. Biol Psychiatry. 2012 Jun 1;71(11):939-46.

30. Mathew SJ, Murrough JW, aan het Rot M, Collins KA, Reich DL, Charney DS. Riluzole for relapse prevention following intravenous ketamine in treatment-resistant depression: a pilot randomized, placebo-controlled continuation trial. Int J Neuropsychopharmacol. 2010 Feb;13(1):71-82.

31. Murrough JW, losifescu DV, Chang LC, Al Jurdi RK, Green CE, Perez AM, et al. Antidepressant efficacy of ketamine in treatment-resistant major depression: a two-site randomized controlled trial. Am J Psychiatry. 2013 0ct;170(10):113442.

32. aan het Rot M, Collins KA, Murrough JW, Perez AM, Reich DL, Charney DS, et al. Safety and efficacy of repeated-dose intravenous ketamine for treatment-resistant depression. Biol Psychiatry. 2010 Jan;67(2):139-45.

33. Ibrahim L, Diazgranados N, Franco-Chaves J, Brutsche N, Henter ID, Kronstein $\mathrm{P}$, et al. Course of improvement in depressive symptoms to a single intravenous infusion of ketamine vs add-on riluzole: results from a 4-week, double-blind, placebo-controlled study. Neuropsychopharmacology. 2012 May;37(6):1526-33.

34. Sanacora C, Zarate CA, Krystal JH, Manji HK. Targeting the glutamatergic system to develop novel, improved therapeutics for mood disorders. Nat Rev 
Drug Discov. 2008 May; $7(5): 426-37$.

35. Correll GE, Futter GE. Two case studies of patients with major depressive disorder given low-dose (subanesthetic) ketamine infusions. Pain Med. 2006 Jan-Feb; $7(1): 92-5$.

36. Glue $P$, Gulati A, Le Nedelec M, Duffull S. Dose- and exposure-response to ketamine in depression. Biol Psychiatry. 2011 Aug 15;70(4):e9-10.

37. Goforth HW, Holsinger T. Rapid relief of severe major depressive disorder by use of preoperative ketamine and electroconvulsive therapy. J ECT. 2007 Mar;23(1):23-5.

38. Machado-Vieira R, Manji HK, Zarate CA. The role of the tripartite glutamatergic synapse in the pathophysiology and therapeutics of mood disorders. Neuroscientist. 2009 0ct;15(5):525-39.

39. Ibrahim L, Diazgranados N, Luckenbaugh DA, Machado-Vieira R, Baumann J, Mallinger AG, et al. Rapid decrease in depressive symptoms with an $\mathrm{N}$-methyl-d-aspartate antagonist in ECT-resistant major depression. Prog Neuropsychopharmacol Biol Psychiatry. 2011 Jun 1;35 (4):1155-9.

40. Phelps LE, Brutsche N, Moral JR, Luckenbaugh DA, Manji HK, Zarate CA Jr. Family history of alcohol dependence and initial antidepressant response to an N-methyl-D-aspartate antagonist. Biol Psychiatry. 2009 Jan 15;65(2):181-4. 41. Salvadore G, Cornwell BR, Colon-Rosario V, Coppola R, Grillon C, Zarate CA $J r$, et al. Increased anterior cingulate cortical activity in response to fearful faces: a neurophysiological biomarker that predicts rapid antidepressant response to ketamine. Biol Psychiatry. 2009 Feb 15;65(4):289-95.

42. Salvadore G, van der Veen JW, Zhang Y, Marenco S, Machado-Vieira R, Baumann J, et al. An investigation of amino-acid neurotransmitters as potential predictors of clinical improvement to ketamine in depression. Int J Neuropsy- chopharmacol. 2012 Sep;15(8):1063-72.

43. Krystal JH, Petrakis IL, Krupitsky E, Schutz C, Trevisan L, D'Souza DC. NMDA receptor antagonism and the ethanol intoxication signal: form alcoholism risk to pharmacotherapy. Ann N Y Acad Sci. 2003 Nov; 1003:176-84.

44. Aan Het Rot M, Zarate CA Jr, Charney DS, Mathew SJ. Ketamine for depression: Where do we go from here? Biol Psychiatry. 2012 0ct;72(7):537-47. 45. Petrakis IL, Limoncelli D, Gueorguieva R, Jatlow P, Boutros NN, Trevisan L, et al. Altered NMDA glutamate receptor antagonist response in individuals with a family vulnerability to alcoholism. Am J Psychiatry. 2004 0ct;161(10):1776-82. 46. Howland RH. Ketamine for the treatment of depression. J Psychosoc Nurs Ment Health Serv. 2013 Jan;51(1):11-4.

47. Wohleb ES, Gerhard D, Thomas A, Duman RS. Molecular and cellular mechanisms of rapid-acting antidepressants ketamine and scopolamine. Curr Neuropharmacol. $2016 \mathrm{Mar}$ 8. [Epub ahead of print]

48. Carreno FR, Donegan JJ, Boley AM, Shah A, DeGuzman M, Frazer A, et al. Activation of a ventral hippocampus-medial prefrontal cortex pathway is both necessary and sufficient for an antidepressant response to ketamine. Mol Psychiatry. 2015 Dec 1. [Epub ahead of print]

49. Harraz MM, Tyagi R, Cortés P, Snyder SH. Antidepressant action of ketamine via $\mathrm{mTOR}$ is mediated by inhibition of nitrergic Rheb degradation. Mol Psychiatry. 2016 Mar;21(3):313-9.

50. Monreal M, Davant E. Thrombotic complications of central venous catheters in cancer patients. Acta Haematol. 2001;106(1-2):69-72.

51. Kurul S, Saip P, Aydin T. Totally implantable venous-access ports: local problems and extravasation injury. Lancet Oncol. 2002 Nov;3(11):684-92.

\footnotetext{
Acknowledgments

The authors would like to thank Saba University School of Medicine for endorsing the publication of this review article.

Conflict of Interest Statement at Funding

The authors have no funding, financial relationships, or conflicts of interest to disclose.

Author Contributions

Conceptualization, Critical revision of the manuscript, Approval of the final version: PAT, VH. Data collection, Data analysis and interpretation, Writing: PAT. Administrative/technical advice: VH.

Cite as:

Twohig PA, Huckfeldt V. Using oral and intranasal dosage forms of ketamine for managing treatment-resistant depression: a review of the literature. Int J Med Students. 2016 May-Aug;4(2):64-71.
} 